\title{
Retraction Note: Photon-phonon anti-stokes upconversion of a photonically, electronically, and thermally isolated opal
}

\author{
Michelle R. Stem ${ }^{1}$ (])
}

Published online: 28 August 2019

○) Springer-Verlag GmbH Germany, part of Springer Nature 2019
Publisher's Note Springer Nature remains neutral with regard to jurisdictional claims in published maps and institutional affiliations.

The Editor-in-Chief has retracted this article because postpublication review has shown that there are serious flaws with respect to the acquisition of data through the instrumentation used. The lack of sufficient information on experimental procedures makes it impossible to reproduce the author's approach. For example, it is not defined which portion of light is analysed in the spectral measurements shown in the article. As a consequence the interpretation of the results (e.g. in terms of "microlasing") must be considered unsound. The author does not agree with this retraction.

The original article can be found online at https://doi.org/10.1007/ s00340-016-6392-1.

Michelle R. Stem

mrstem@completeconsultingservices.com

1 Complete Consulting Services LLC, PO Box 412,

Big Rapids, MI 49307, USA 